\title{
Periodic Paralysis: A Case Report of Normokalemic Presentation in a Young Girl
}

\author{
Lucio Ceglie, Roberta Patacchiola, Daniela Iannucci, Miriana Guarino, Lorenzo Sansone, Maria \\ Chiara Sgarrella, Francesco Chiarelli* and Annalisa Blasetti \\ Department of Pediatrics, University of Chieti, Italy
}

*Corresponding author: Francesco Chiarelli, Department of Pediatrics, University of Chieti, Italy

\section{ARTICLE INFO}

Received: 蔧April 10, 2021

Published: April 21, 2021

Citation: Lucio C, Roberta P, Daniela I, Miriana G, Francesco C, et al., Periodic Paralysis: A Case Report of Normokalemic Presentation in a Young Girl. Biomed J Sci \& Tech Res 35(2)-2021. BJSTR. MS.ID.005672.

Keywords: Hypokalemia; Periodic Paralysis; Transient Paralysis; Muscular Weakness; Muscular Pain; Creatine Phosphokinase; CACNA1S Gene

Abbreviations: Normal PP: Normokalemic Periodic Paralysis; HyperPP: Hyperkalemic Periodic Paralysis; HypoPP: Hypokalemic Periodic Paralysis; n.v.: Normal Value; EEG: Electroencephalogram

\section{ABSTRACT}

The skeletal muscle channelopathies represent a rare group of neuromuscular disorders which are caused by genetic mutations regarding voltage-gated ion channels, which play an important role in muscle membrane depolarization. Muscle channelopathies are broadly divided into 2 main categories: nondystrophic myotonias (NDM) and periodic paralysis (PP). Periodic paralysis (PP) are rare autosomal dominant neuromuscular disorders, characterized clinically by periodic attacks of muscle weakness in concomitance with serum potassium level alterations. It is possible to distinguish normokalemic, hyperkalemic and hypokalemic paralysis. PP is caused by genetic mutations in voltage-gate ion channels like sodium, potassium, and calcium channels, which are determinant for muscle membrane depolarization. The most common genes involved in pathogenesis are CACN1S, SCN4A and KCNJ2, encoding calcium, sodium, and potassium channels (Table 1). Moreover, paralysis related to serum potassium values may also occur in thyreotoxicosis [1], Liddle syndrome, Gitelman syndrome, primary hyperaldosteronism, and acid-base balance disorders. In this case report, we describe a case of transient paralysis and muscular weakness of both upper and lower limbs after a high carbohydrate meal on the day before clinical presentation. Potassium level was normal at the hospital admission, while high levels of creatine phosphokinase, (CPK), Myoglobin, and Aspartate Aminotransferases (AST) was observed.

A missense mutation in CACNA1S exon 11 was identified. This case supports the importance of a correct family history, muscular enzyme analysis and genetic study in a normokalemic presentation of periodic paralysis.

\section{Background}

Muscular channelopathies may have two different clinical manifestations: sudden attacks of flaccid transient paralysis, often associated with abnormal serum potassium levels (periodic paralysis) and muscular stiffness (myotonia) [2,3]. In channelopathies mutations commonly involve calcium, chlorine, sodium, and potassium channels. They have autosomal dominant inheritance. The gene loci include CACN1AS (calcium channel) $[4,5]$ located on chromosome 1, CLCN1 (chlorine channel) [1,6] on chromosome [7] SCN4A [4,5,7,8] and KCNJ2 [9] (sodium and potassium channels, respectively) on chromosome 17. Hypokalemic periodic paralysis is a rare disorder with a prevalence of $1: 100.000$ [1] and a large spectrum of penetrance which is expressed in a wide variety of correlation between genotype and phenotype [10]. Moreover, the quality of life in these patients can be impaired for a chronic and progressive muscular dystrophy $[11,12]$. Periodic paralysis is usually classified on clinical and laboratory criteria (serum potassium values and response to potassium administration) and on genetic criteria. Reliyng on serum potassium levels, periodic paralysis is classified in mormokalemic (NormoPP), hyperkalemic (HyperPP) and hypokalemic (HypoPP) $[1,2]$. HyperPP, NormoPP and $10 \%$ cases of HypoPP are related to SCN4A mutations7, 70\% cases of HypoPP are related to CACN1AS mutations $[3,4]$, on the other hand KCNJ2 mutations are decisive for Andersen-Tawill Syndrome [9,12]. 
Table 1: Main channelopathies and loci involved. In channelopathies mutations interested calcium, sodium and potassium channels. The gene loci involved are CACN1AS (calcium channel) located on chromosome 1, SCN4A and KCNJ2 (sodium and potassium channels, respectively) located on chromosome 17. The table describes different clinical presentations related to specific gene loci mutations $[28,29]$.

\begin{tabular}{|c|c|c|c|}
\hline Gene - Protein & Membrane Channels & Loci & Clinical Presentation \\
\hline $\begin{array}{l}\text { CACNA1S, CACNL1A3 - } \\
\text { Cav1.1 }[33,5]\end{array}$ & $\begin{array}{l}\alpha \text {-subunit of dihydropyridine sensitive } \\
\text { L-type voltage-gated calcium channel }\end{array}$ & $1 q 31-32$ & $\begin{array}{c}\text { Hypokalemic periodic paralysis type } 1 \text { (hypoPP1) } \\
\text { Malignant hyperthermia } \\
\text { Congenital myopathy }[26]\end{array}$ \\
\hline $\begin{array}{l}\text { SCN4A - Nav1.4 } \\
{[4,5,7,27,30,31]}\end{array}$ & $\begin{array}{l}\alpha \text {-subunit of voltage-gate sodium } \\
\text { channel }\end{array}$ & $\begin{array}{l}1 \mathrm{q} 31-32 \\
17 \mathrm{q} 23-25\end{array}$ & $\begin{array}{c}\text { Hyperkalemic periodic paralysis } \\
\text { Hypokalemic periodic paralysis type } 2 \text { (hypoPP2) } \\
\text { Congenital paramyotonia } \\
\text { Acetazolamide responsive myasthenic syndrome [25] } \\
\text { Sodium channel myotonia }[26,27,29] \\
\text { Recessive congenital myopathy }\end{array}$ \\
\hline KNCJ2 - Kir2.1 [1,16,35] & $\begin{array}{l}\text { Inwardly rectifying potassium } \\
\text { channel }\end{array}$ & $17 q 23$ & $\begin{array}{l}\text { Andersen-Tawil syndrome [35] } \\
\text { Familial atrial fibrillation } 9 \\
\text { Short QT syndrome } 3\end{array}$ \\
\hline KNCJ5 - Kir3.4 [1,16,35] & $\begin{array}{l}\text { Inwardly rectifying potassium } \\
\text { channel }\end{array}$ & & Andersen-Tawil syndrome [35] \\
\hline KNCJ18 -Kir2.6 [1,16,35] & $\begin{array}{l}\text { Inwardly rectifying potassium } \\
\text { channel }\end{array}$ & & $\begin{array}{c}\text { Thyrotoxic periodic paralysis [32] } \\
\text { Hypokalemic periodic paralysis }\end{array}$ \\
\hline
\end{tabular}

Clinically, HypoPP begins on the first or second decade and decrease in frequency after forty years of age [13].

Attacks are characterized by flaccid paralysis, usually occurring on awakening during the night or at early-morning, focal or generalized weakness which lasts for hours (occasionally days) with a gradual resolution $[1,2,14,15]$. Occurrence may be spontaneous or provoked by prolonged rest after vigorous exercise, carbohydrate-rich meal on the previous day. Triggers include viral infections, sleep deprivation, period in women and drugs (e.g. beta agonists, corticosteroids and insulin) [1,16]. HyperPP differs from HypoPP for an earlier age of onset (first decade) $[1,16]$. Weakness is usually generalized and last 1-4 hours (infrequently days). They are triggered by rest after exercise, K-rich foods, stress, and fatigue. Among episodes of weakness, eyelid myotonia may be the only clinical sign. Electrical myotonia is found in 50-75\% of patients. Typically, hyperkalemic attacks are associated with elevated ictal serum potassium level, but many children have normal potassium level during attacks. For those reason, laboratory approach is important to distinguish them $[1,16,17]$.

In our patient a transient paralysis and muscular weakness with elevated levels of creatine phosphokinase, (CPK), Myoglobin, and Aspartate Aminotransferases (AST), concurrently with normal potassium serum levels was observed.

\section{Case Presentation}

A 12-years old Caucasian girl was admitted to our clinic unit with acute onset of transient paralysis of all four limbs arisen on the awakening and the followed by paresthesia's, motor impairment without loss or disturbances of consciousness $[1,16]$. There was also muscular pain in both legs and arms without dysphagia, dysphonia, history of suggestive symptoms such as ocular, sensory, cerebellar, or cranial nerve involvement. Moreover, these symptoms improved after salt supplement intake. Family history was suggestive for muscle symptoms (not confirmed Liddle syndrome) [18]. Her grandfather, father and one of her uncles had similar mild paralytic attacks; on the other hand, another uncle presented more severe symptoms, including dyspnea and respiratory muscles involvement. She had a significant past medical history for transient paralysis. One episode occurred after an acute diarrhea and two of them during physical exercise with an improvement after few hours. On examination, skin was not affected by cutaneous alterations or lesions. Cardiovascular, pulmonary, and abdominal examinations were not compromise [19]. Neurological exam revealed a normal deep tendon reflexes and global and segmental strength of both upper and lower extremities $[1,16,20]$. There were not palpable goiter or tremors.

Laboratory findings of our case are shown in (Table 2). No ECG alterations was recorded [19,20]. Arterial pressure levels control were normal as well as the electroencephalogram. During hospitalization, the girl never showed neurological or muscular symptoms, so we prescribed oral potassium supplement only in case of need [21]. We planned a mutation screening for hypokalemic periodic paralysis. Genomic DNA was extracted from the peripheral blood and also other family members are tested with 
PCR amplification and direct sequencing of CACNA1S exon 11, the This mutation has been found in our patient and also in her father, most frequent gene involved in hypokalemic periodic paralysis. in two uncles, grandfather and an asymptomatic cousin (Figure 1).

Table 2: Laboratory tests performed and them normal range in relation to our patient's age.

\begin{tabular}{|c|c|c|c|}
\hline Laboratory tests & Patient's value (first sample) & Patient's value (second sample) & Normal range \\
\hline Potassium, mmol/L & 3,9 & & $3,5-5,0$ \\
\hline free thyroxin (fT4), ng/dl & 1,02 & & $0,7-1,7$ \\
\hline free triiodothyronine (fT3), $\mathrm{pg} / \mathrm{dl}$ & 3,82 & & $2-4,9$ \\
\hline $\mathrm{TSH}, \mathrm{microUI} / \mathrm{ml}$ & 2,8 & & $0,25-4,5$ \\
\hline creatine phosphokinase (CPK), U/I & 569 & 249 & $30-135$ \\
\hline AST, U/I & 60 & 41 & $14-36$ \\
\hline ALT, U/I & 26 & & Nov-66 \\
\hline Venous blood gas: & & & \\
\hline $\mathrm{pH}$ & 7,333 & & $7,350-7,450$ \\
\hline $\mathrm{PaCO} 2, \mathrm{mmHg}$ & 54,3 & & $35,0-45,0$ \\
\hline $\mathrm{PaO} 2, \mathrm{mmHg}$ & 21,2 & & $80-100$ \\
\hline $\mathrm{HCO}-, \mathrm{mmol} / \mathrm{L}$ & 28,2 & & $22,0-26,0$ \\
\hline $\mathrm{K}, \mathrm{mmol} / \mathrm{L}$ & 3,76 & & $3,5-5,0$ \\
\hline Serum aldosterum, pg/ml & 135 & & $40-150$ \\
\hline Proteinuria, mg/dl & 30 & & Oct-20 \\
\hline $\begin{array}{l}\text { Echovirus and Coxsackie virus IgM } \\
\text { and IgG }\end{array}$ & & absent & \\
\hline Myoglobin, ng/ml & & 107 & $9-82,5$ \\
\hline
\end{tabular}

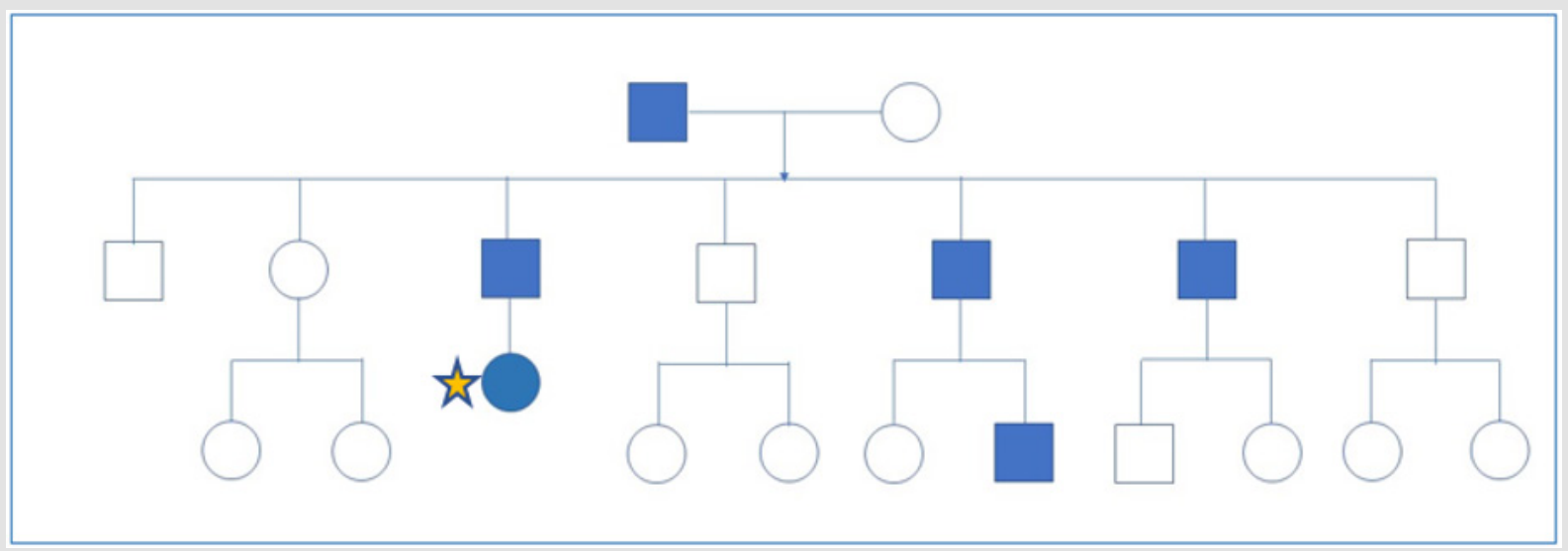

Figure 1: Family pedigree showing three generations. Squares: man; circles: women. Star: our patient. Blue indicates patients with hypokalemic periodic paralysis.

\section{Conclusion}

Patient described in this report had a positive family history for muscle symptoms but there was no established diagnosis in her family members. Since the presence of poor clinical signs and normal serum potassium values at admission, we performed laboratory and instrumental tests to find out possible secondary causes for the paralytic event $[1,16]$. A main cause of hypokalemia is acid-base disorder, so we tested blood gas analysis which showed compensated acidosis. This finding, associated to normal blood pressure values, has led us to exclude the diagnostic hypothesis of Liddle syndrome, postulated in the past for relative [22]. Liddle syndrome is one of the causes of muscular weakness, especially in lower limbs, associated with hypokalemia that occurs with metabolic alkalosis, hypertension, and hypokalemia. Same clinical manifestations are present in primary hyperaldosteronism, but aldosterone serum value in our patent was normal. Having regard to the symptoms' regression with the assumption of salt supplements, we concluded that it was a paralytic form due to hypokalemia $[1,16,22]$. For this reason, we investigated the major forms of hypokalemia. Besides Liddle syndrome and primary hyperaldosteronism, hypokalemia can be found in Gitelman 
syndrome associated with metabolic alkalosis, hypomagnesemia and hypocalciuria. In our patient, we did not find any alteration in urinary and blood electrolytes levels [23-31]. Thyrotoxicosis is another one of the main causes of secondary periodic hypokalemic paralysis [32].

Diagnosis is based on laboratory finding of altered thyroid hormones values (fT3, fT4, TSH); for these parameters there is no alteration in our patient. Instead, parameters index of muscle damage like CPK, myoglobin and AST were abnormal. It is postulated that hypokalemia causes muscle ischemia resulting in an increase in serum CPK. Elevated CPK levels during the recovery phase can be used to identify symptomatic patients in whom serum potassium becomes normal after or during hypokalemic paralysis. The heterozygous G>A (Arg528His) CACNA1S gene missense mutation identified in our patient in often triggered by a high carbohydrate meal, [33] as happened in our case. A peculiarity of our case is represented by higher levels of CPK, AST and myoglobin, contrary to what was reported in the series of Alhasan, et al. [13,33]. Excluding secondary causes and considering familiar paralytic episodes, genetic analysis in our patient and in her family was performed $[23,24]$. Genomic DNA was extracted from patient's peripheral blood and from members of her family using PCR amplification and direct sequencing of CACNA1S exon 11 $[5,33]$.Finally, periodic paralysis in women is mostly asymptomatic (about $50 \%$ of cases) and normokalemic presentation is rarer than other clinical presentations. Therefore, it is important to have a clinical suspicion of periodic paralysis, after other causes of muscle weakness have been ruled out [18].

\section{Consent}

Written informed consent was obtained from parents of the patient for the publication of this case report. A copy of the written consent is available for being reviewed by the Editor-in-Chief of this journal.

\section{Competing Interests}

The authors declare that they have no competing interests.

\section{References}

1. Thor MG, Vivekanandam V, Sampedro Castañeda M, Tan SV, Suetterlin $\mathrm{K}$, et al. (2019) Myotonia in a patient with a mutation in an S4 arginine residue associated with hypokalaemic periodic paralysis and a concomitant synonymous CLCN1 mutation. Sci Rep 9(1): 17560.

2. Phuyal P, Nagalli S (2021) Hypokalemic Periodic Paralysis. Treasure Island (FL). StatPearls.

3. Statland JM, Barohn RJ (2013) Muscle channelopathies: the nondystrophic chas and periodic paralyses. Continuum (Minneap Minn) 19(6 Muscle Disease), pp. 1598-1614.

4. Ke T, Gomez CR, Mateus HE, Castano JA, Wang QK (2009) Novel CACNA1S mutation causes autosomal dominant hypokalemic periodic paralysis in a South American family. J Hum Genet 54: 660-664.
5. Wang XY, Ren BW, Yong ZH, Xu HY, Fu QX, et al. (2015) Mutation analysis of CACNA1S and SCN4A in patients with hypokalemic periodic paralysis. Mol Med Rep 12: 6267-6274.

6. Maggi L, Ravaglia S, Farinato A, Brugnoni R, Altamura C, et al. (2017) Coexistence of CLCN1 and SCN4A mutations in one family suffering from myotonia. Neurogenetics 18: 219-225.

7. Matthews E, Portaro S, Ke Q, Sud R, Haworth A, etal. (2011) Acetazolamide efficacy in hypokalemic periodic paralysis and the predictive role of genotype. Neurology 77: 1960-1964.

8. Gregor Andelfinger, Andrew R Tapper, Richard C Welch, Carlos G Vanoye, Alfred L George, et al. (2002) KCNJ2 Mutation Results in Andersen Syndrome with Sex-Specific Cardiac and Skeletal Muscle Phenotypes. The American Journal of Human Genetics 71(3): 663-668.

9. Morales F, Pusch M (2020) An Up-to-Date Overview of the Complexity of Genotype-Phenotype Relationships in Myotonic Channelopathies. Front Neurol 17(10): 1404

10. Cavel Greant D, Lehmann Horn F, Jurkat Rott K (2012) The impact of permanent muscle weakness on quality of life in periodic paralysis: A survey of 66 patients. Acta Myol 31: 126-133.

11. Sansone VA, Ricci C, Montanari M, G Apolone, M Rose, et al. (2012) Measuring quality of life impairment in skeletal muscle channelopathies. Eur J Neurol 19(11): 1470-1476.

12.Cannon SC (2015) Channelopathies of Skeletal Muscle Excitability. Compr Physiol 5(2): 761-790.

13. Fialho D, Griggs RC, Matthews E (2018) Periodic paralysis. Handb Clin Neurol 148: 505-520.

14. Ginanneschi F, Mignarri A, Lucchiari S, Ulzi G, Comi GP, et al. (2017) Neuromuscular excitability changes produced by sustained voluntary contraction and response to mexiletine in myotonia congenita. Neurophysiol Clin 47(3): 247-252.

15. Statland JM, Fontaine B, Hanna MG, Johnson NE, Kissel JT, et al. (2018) Review of the Diagnosis and Treatment of Periodic Paralysis. Muscle Nerve 57: 522-530.

16. Charles G, Zheng C, Lehmann Horn F, K Jurkat-Rott, J Levitt (2013) Characterization of hyperkalemic periodic paralysis: a survey of genetically diagnosed individuals. J Neurol 260(10): 2606-2613.

17. Chalissery AJ, Munteanu T, Langan Y, Brett F, Redmond J (2018) Diverse phenotype of hypokalaemic periodic paralysis within a family. Pract Neurol 18(1): 60-65.

18. Andersen ED, Krasilnikoff PA, Overvad H (1971) Intermittent muscular weakness, extrasystoles, and multiple developmental anomalies. Acta Pædiatrica 60: 559-564.

19. Basali D, Prayson RA (2015) Episodic weakness, and vacuolar myopathy in hypokalemic periodic paralysis. J Clin Neurosci 22: 1846-1847.

20. Sansone V, Meola G, Links TP (2008) Treatment for periodic paralysis. Cochrane Database Syst Rev 2008: CD005045.

21. Rolim AL, Lindsey SC, Kunii IS, Fujikawa AM, Soares FA, et al. (2010) Ion channelopathies in endocrinology: Recent genetic findings and pathophysiological insights. Arq Bras Endocrinol Metabol 54(8): 673681.

22. Sansone VA (2019) Episodic Muscle Disorders. Continuum (Minneap Minn) 25(6): 1696-1711.

23. Matthews E, Silwal A, Sud R, Michael G Hanna, Adnan Y Manzur, et al. (2017) Skeletal muscle channelopathies: Rare disorders with common pediatric symptoms. J Pediatr 188: 181-185.

24. Matthews E, Portaro S, Ke Q, Sud R, Haworth A, etal. (2011) Acetazolamide efficacy in hypokalemic periodic paralysis and the predictive role of genotype. Neurology 77: 1960-1964. 
25. Conravey A, Santana Gould L (2010) Myotonia congenita and myotonic dystrophy: Surveillance and management. Curr Treat Options Neurol 12 : 16-28.

26. Jurkat Rott K, Holzherr B, Fauler M (2010) Sodium channelopathies of skeletal muscle result from gain or loss of function. Pflugers Arch 460: 239-248.

27. Cannon SC (2010) Voltage-sensor mutations in channelopathies of skeletal muscle. J Physiol 588(pt 11): 1887-1895.

28. Johnson NE (2019) Myotonic muscular dystrophies. Continuum (Minneap Minn) 25(6, Muscle and Neuromuscular Junction Disorders), pp. 1682-1695.

29. Groome JR, Lehmann Horn F, Fan C, Wolf M, Winston V, et al. (2014) Nav1.4 mutations cause hypokalaemic periodic paralysis by disrupting IIIS4 movement during recovery. Brain 137: 998-1008.

ISSN: 2574-1241

DOI: 10.26717/BJSTR.2021.35.005673

Francesco Chiarelli. Biomed J Sci \& Tech Res

(C) (P) This work is licensed under Creative Commons Attribution 4.0 License

Submission Link: https://biomedres.us/submit-manuscript.php
30. Bayless Edwards L, Winston V, Lehmann Horn F, Arinze P, Groome JR, et al. (2018) Nav1.4 DI-S4 periodic paralysis mutation R222W enhances inactivation and promotes leak current to attenuate action potentials and depolarize muscle fibers. Sci Rep 8(1): 10372.

31. Tella SH, Kommalapati A (2015) Thyrotoxic periodic paralysis: An underdiagnosed and under-recognized condition. Cureus 7: e342.

32. Richards S, Aziz N, Bale S, Bick D, Das S, et al. (2015) Standards and guidelines for the interpretation of sequence variants: A joint consensus recommendation of the American College of Medical Genetics and Genomics and the Association for Molecular Pathology. Genet Med 17(5): 405-424.

33. Alhasan KA, Abdallah MS, Kari JA, Bashiri FA (2019) Hypokalemic periodic paralysis due to CACNA1S gene mutation. Neurosciences (Riyadh) 24(3): 225-230.

\begin{tabular}{ll} 
BIOMEDICAL & \multicolumn{1}{c}{ Assets of Publishing with us } \\
RESEARCHES & - Global archiving of articles \\
\hline Immediate, unrestricted online access \\
- Rigorous Peer Review Process
\end{tabular}

